\title{
Effect of production system on welfare traits, growth performance and meat quality of ducks
}

\author{
Yujie Chen ${ }^{1,2}$, Chen Aorigele ${ }^{1}$, Feng Yan $^{2}$, Yan $\mathrm{Li}^{2}$, Peng Cheng ${ }^{2}$ \& Zhili Qi ${ }^{2 \#}$ \\ ${ }^{1}$ Department of Animal Nutrition, College of Animal Science, Inner Mongolia Agricultural University, \\ Hohhot 010018, P.R. China \\ ${ }^{2}$ Department of Animal Nutrition and Feed Science, College of Animal Science and Technology, \\ Huazhong Agricultural University, Wuhan 430070, P.R. China
}

(Received 20 February 2014; Accepted 6 May 2015; First published online 6 June 2015)

Copyright resides with the authors in terms of the Creative Commons Attribution 2.5 South African Licence.
See: http://creativecommons.org/licenses/by/2.5/za
Condition of use: The user may copy, distribute, transmit and adapt the work, but must recognise the authors and the South African
Journal of Animal Science.

\begin{abstract}
The effects of production system on welfare traits, growth performance and meat quality of ducks were explored. A total of 120 newly hatched ducklings were randomly assigned to three groups: i) floor-reared system (FRS); ii) welfare-reared system (WRS) and iii) net-reared system (NRS) ( $n=8$ ducklings/pen, 5 pens/group). In the FRS, ducks were reared on sawdust bedding that was changed every 2 - 3 days. The WRS was similar to the FRS, the difference being the addition of environmental enrichment devices such as perches, coloured balloons and ribbons. In the NRS, ducks were reared on plastic nets on a bamboo bed, and their droppings were cleaned daily with water. After $35 \mathrm{~d}$, welfare traits, growth performance and meat quality of the ducks were measured. Moving and playing durations of WRS ducks were longer than FRS and NRS ducks. Bathing and feather pecking durations of NRS ducks were longer than FRS and WRS ducks. Duck feather quality was greater and gait defects were reduced in NRS system compared with FRS and WRS systems. Fluctuating asymmetry (FA) was not affected by the production system. Growth performance was not significantly different between FRS and WRS systems. Average daily weight gain of FRS ducks was higher than in NRS ducks. Feed conversion ratio of FRS ducks was lower than in NRS ducks. There was no difference in acidity, conductivity of pectoralis and leg muscle, and drip loss among the production systems. The conclusion was that NRS proved to be the best production system on welfare traits, while WRS and FRS were the best production systems on growth performance.
\end{abstract}

Keywords: Drip loss, feather quality, fluctuating asymmetry, gait defect, production system

\# Corresponding author: zhiliqi@mail.hzau.edu.cn

\section{Introduction}

Growth of the duck industry has increased substantially during the past 20 years. There are 2.7 billion ducks in the world, with about 2.08 billion in China. In 2010 world duck meat production was about 4.0 million, of which 2.8 million tons was produced in China (FAO, 2011). In order to meet the demand for duck meat, duck production has become more intensive. The increased densities of ducks in such production systems have resulted in changes in duck behaviour with decreased duck welfare and lower meat quality. Moreover, they have resulted in greater incidence of footpad dermatitis, scratches, bruising, poorer feathering, and condemnations (Xie et al., 2014). Therefore to meet the requirements for animal welfare and food safety, appropriate production systems must be developed.

The aim of this study was to investigate the effects of three production systems on welfare traits, growth performance and meat quality of ducks. These welfare traits consisted of daily behaviour, feather condition score, gait score and fluctuating asymmetry (FA). The objective of this study was to provide quantitative and qualitative data on production systems and their impact on selected welfare indices of ducks.

\section{Materials and Methods}

The experiment was approved by Huazhong Agricultural University, China.

A total of 120 newly hatched Cherry Valley ducklings were randomly assigned to three production systems: i) floor-reared system (FRS); ii) welfare-reared system (WRS) and iii) net-reared system (NRS) ( $n=$ 8 ducklings/pen, 5 pens/system). Each pen had the same area, temperature and lighting conditions. In the 
FRS, ducks were reared on sawdust bedding that was changed every 2 - 3 days. The WRS was similar to the FRS, but environmental enrichment devices such as perches, coloured balloons and ribbons were added. In the NRS, ducks were reared on plastic net on a bamboo bed, and their droppings were cleaned with water daily. The ducks were supplied with enough water to drink and to bath in basins.

Ducks were fed a maize-soybean meal diet without added growth promoter, coccidiostat or enzymes (Table 1), according to the nutritional recommendations for ducks (NRC, 1994). Feed and water were provided ad libitum. The pre-experiment period was 6 days, during which ducklings were vaccinated against avian influenza. The experimental period was 35 days, and feed consumption was recorded daily.

Table 1 Ingredient composition ( $\mathrm{g} / \mathrm{kg}$ ) of basal diet (air-dried basis)

\begin{tabular}{|c|c|c|}
\hline Ingredients (g/kg) & $\begin{array}{l}\text { Starter diet }{ }^{1} \\
0-2 \text { weeks }\end{array}$ & $\begin{array}{c}\text { Grower diet }{ }^{2} \\
3-5 \text { weeks }\end{array}$ \\
\hline Maize & 579 & 634 \\
\hline Soybean meal & 270 & 170 \\
\hline Wheat bran & 50 & 80 \\
\hline Rapeseed meal & 60 & 80 \\
\hline $\mathrm{CaHPO}_{4}$ & 11 & 8 \\
\hline Limestone powder & 12 & 12 \\
\hline Salt & 4.0 & 3.5 \\
\hline Lysine $\mathrm{HCl}$ & 2.0 & 1.0 \\
\hline Methionine & 1.6 & 1.0 \\
\hline Vitamin and mineral premix & 10 & 10 \\
\hline Total (g) & 1000 & 1000 \\
\hline \multicolumn{3}{|l|}{ Nutrition level $^{3}$} \\
\hline Metabolizable energy (MJ/kg) & 12.1 & 12.3 \\
\hline Crude protein & 195 & 169 \\
\hline Calcium & 8.3 & 7.5 \\
\hline Phosphorus & 6.4 & 5.8 \\
\hline Avail. phosphorus & 3.9 & 3.4 \\
\hline
\end{tabular}

\footnotetext{
${ }^{1}$ Vitamin and mineral premixes supplied per kilogram diet: retinol acetate $3.9 \mathrm{mg}$; cholecalciferol $0.165 \mathrm{mg}$; DL-a-tochopheryl acetate $83 \mathrm{mg}$; riboflavin $10 \mathrm{mg}$; menadione $2 \mathrm{mg}$; pantothenic acid $8 \mathrm{mg}$; niacin $42 \mathrm{mg}$; folic acid $1.6 \mathrm{mg}$; biotin $0.05 \mathrm{mg}$; iron $80 \mathrm{mg}$; manganese $80 \mathrm{mg}$; copper $5 \mathrm{mg}$; zinc $70 \mathrm{mg}$; iodine $3 \mathrm{mg}$; cobalt $1 \mathrm{mg}$; selenium $0.2 \mathrm{mg}$.

${ }^{2}$ Vitamin and mineral premixes supplied per kilogram diet: retinol acetate $2.7 \mathrm{mg}$; cholecalciferol $0.15 \mathrm{mg}$; DL-a-tochopheryl acetate $79 \mathrm{mg}$; riboflavin $8 \mathrm{mg}$; menadione $2 \mathrm{mg}$; pantothenic acid $3.2 \mathrm{mg}$; niacin $11 \mathrm{mg}$; folic acid $1.5 \mathrm{mg}$; biotin $0.05 \mathrm{mg}$; iron $60 \mathrm{mg}$; manganese $50 \mathrm{mg}$; copper $6 \mathrm{mg}$; zinc $60 \mathrm{mg}$; iodine $2 \mathrm{mg}$; cobalt $1 \mathrm{mg}$; selenium $0.18 \mathrm{mg}$.

${ }^{3}$ Crude protein, calcium and total phosphorus levels of the feedstuffs are analysed values. Other nutrient levels are theoretical values.
}

The effects on daily behaviour of the three production systems were observed. Measurements consisted of selected welfare traits, growth performance and meat quality. These welfare traits consisted of daily behaviour, feather condition score, gait score and fluctuating asymmetry. Daily behaviour consisted of moving, playing, drinking, bathing and feather pecking (Jones et al., 2009; Amado et al., 2011). Before observation began, three people were trained for three days in recording behaviour to minimize variation. These observations were carried out in each group by visual appraisal. Two ducks were randomly chosen from each group and marked with coloured Velcro rings. For seven consecutive days before the end of the experiment, duck behaviour was observed for $100 \mathrm{~min} /$ day, from 9:20 to11:00. The total time spent on each behaviour criterion in that session was recorded.

Feather condition score was determined as follows: three ducks were randomly chosen from each pen one day before the end of the experiment (day 34). Feather condition score was measured in eight parts of 
the body: head, neck, back, tail, wings, breasts, anus and legs. Tail feathers were scored from 0 to 3 , while the other feathers were scored from 0 to 5, as shown in Table 2 (Wechsler et al., 1998). Gait score was determined as follows: after feather condition score, three duck from each pen, 15 ducks per system, was chosen and placed in a quiet room and the gait score was determined (Table 2) (Kestin et al., 1992; Dawkins et al., 2004). The proportions of ducks with gait scores of 1, 2 or 3 in the three production systems were recorded and calculated.

Table 2 Scoring method for feather condition score and gait score

\begin{tabular}{llll}
\hline Score & \multicolumn{2}{c}{ Feather condition score (Wechsler et al., 1998) } & \multicolumn{2}{c}{ Tail } & Gait score \\
\cline { 2 - 3 } & \multicolumn{1}{c}{ Other seven parts } & Perfect & $\begin{array}{l}\text { Bird walks with ease, has regular and even } \\
\text { strides and is well balanced } \\
\text { Bird walks with irregular and uneven strides } \\
\text { and appears unbalanced } \\
\text { Bird is reluctant to move and is unable to } \\
\text { walk many strides before sitting down }\end{array}$ \\
3 & Perfect plumage & Damaged & \\
4 & Feathers damaged, no skin area denuded & Feathers & \\
5 & Denuded area up to $3 \mathrm{~cm} \times 3 \mathrm{~cm}$ & missing & \\
\hline
\end{tabular}

Fluctuating asymmetry was detected as follows: 1 duck from each pen, 5 ducks per system that were not scored for feather quality or gait score were selected to determine fluctuating asymmetry on the day before the end of the experiment (day 34). The length of the right and left legs, and leg width were measured with a Vernier calliper. Fluctuating asymmetry values were calculated using the following formula:

$$
\mathrm{FA}=2 \times \frac{|\mathrm{R}-\mathrm{L}|}{\mathrm{R}+\mathrm{L}}
$$

where $F A$ is leg length $(L L), R$ is the length of the right leg, $L$ is the length of the left leg; When the $F A$ was of leg width (LW), $R$ was the width of the right leg, $L$ was the width of the left leg; When the FA was of wing length (WL), $R$ was the length of the right wing, $L$ of the left wing.

Growth performance consisted of average daily feed intake (ADFI), average daily weight gain (ADG), and feed conversion ratio (FCR). Meat quality traits consisted of initial $\mathrm{pH}$, final $\mathrm{pH}$, conductivity and drip loss. The ADFI was determined as follows: $m$ was the total feed consumption of each pen from the beginning to the end of the experiment, $n$ was the number of ducks in each pen, $t$ was the number of days in this period.

$$
\mathrm{ADFI}=\frac{\mathrm{m}}{\mathrm{n} \times \mathrm{t}}
$$

The ADG was determined as follows: $m 1$ was the weight of the ducks in each pen at the end of the experiment and $\mathrm{m} 2$ the weight at the beginning of the experiment, $\mathrm{n}$ was the number of ducks in each pen, and $t$ was the number of days in this period.

The FCR was the ratio of ADFI and ADG.

$$
\mathrm{ADG}=\frac{\mathrm{m} 1-\mathrm{m} 2}{\mathrm{n} \times \mathrm{t}}
$$

When the experiment was finished, the ducks were fasted for $24 \mathrm{~h}$ (but with access to drinking water) before being weighed. The ducks were euthanatized by severing the jugular vein.

The carcasses were divided, and the giblets, leg muscle and pectorals were dissected. Initial $\mathrm{pH}$ and conductivity of leg muscle and pectorals were determined within 45 min by $\mathrm{pH}$ meter (pH-Star, Matthaus, Germany) and conductivity meter (LF-Star, Matthaus, Germany). Then the pectorals were kept in refrigeration at $4{ }^{\circ} \mathrm{C}$. About $13 \mathrm{~g}$ from each of two pieces of leg muscle of each duck were placed into $\mathrm{PE}$ (polythene) tubes, and hung vertically in refrigerator at $4^{\circ} \mathrm{C}$. After $24 \mathrm{~h}$, the $\mathrm{pH}$ of the pectorals and leg muscle, and drip loss of the leg muscle were determined (Wang et al., 2013). The remaining muscles were kept at $-20^{\circ} \mathrm{C}$.

Drip loss was determined as follows: $\mathrm{m} 1$ was the weight of the empty PE tube; $\mathrm{m} 2$ was the weight of leg muscles and PE tube. The PE tube was hung vertically at $4{ }^{\circ} \mathrm{C}$ for $24 \mathrm{~h}$, then the muscle was removed, m3 was the weight of the PE tube and water, drip loss was calculated using the following formula:

$$
\text { Drip loss }=\frac{\mathrm{m} 3-\mathrm{m} 1}{\mathrm{~m} 2-\mathrm{m} 1} \times 100 \%
$$


The results were expressed as mean $\pm S D$. Data were analysed as a complete random design using the general linear model (GLM) procedure of SAS (1995) by balanced one-way ANOVA, with the pen used as the experimental unit for analysis. When the system treatment was significant $(P<0.05)$, the means were compared using Duncan's multiple comparison procedure. The proportion of ducks with gait scores in the three production systems were compared using the chi-square test.

\section{Results}

Duration of moving and playing in the WRS was longer than in the FRS and NRS $(P<0.05)$. Duration of bathing and feather pecking in the NRS was longer than in the FRS and WRS $(P<0.05$; Table 3$)$. The feather condition score of NRS ducks was significantly lower than those in FRS and WRS $(P<0.05$; Table 4). The chi-square test of gait scores indicated that the effects of the three production systems on gait score were different (Table 5). Gait scores of NRS ducks were lower than of FRS and WRS ducks, $(P<0.05$; Table 4). There were no differences in gait scores between WRS and FRS ducks.

Table 3 Behaviour of ducks in three production systems ( $\mathrm{min} / 100 \mathrm{~min}$ )

\begin{tabular}{lrrrr}
\hline \multirow{2}{*}{ Behaviour $^{2}$} & \multicolumn{3}{c}{ Rearing system $^{1}$} & \multirow{2}{*}{$\boldsymbol{P}$-value } \\
\cline { 2 - 4 } & \multicolumn{1}{c}{ Floor } & \multicolumn{1}{c}{ Welfare } & Net & \\
\hline Moving & $9.80^{\mathrm{B}} \pm 1.24$ & $14.99^{\mathrm{A}} \pm 0.91$ & $10.81^{\mathrm{B}} \pm 1.47$ & $<0.0001$ \\
Playing & $4.86^{\mathrm{C}} \pm 0.35$ & $16.17^{\mathrm{A}} \pm 1.36$ & $7.64^{\mathrm{B}} \pm 1.13$ & $<0.0001$ \\
Drinking & $3.39 \pm 0.36$ & $3.81 \pm 0.34$ & $3.78 \pm 0.53$ & 0.1723 \\
Bathing & $0.00^{\mathrm{B}} \pm 0.00$ & $0.00^{\mathrm{B}} \pm 0.00$ & $5.24^{\mathrm{A}} \pm 0.89$ & $<0.0001$ \\
Feather pecking & $3.76^{\mathrm{B}} \pm 0.40$ & $4.13^{\mathrm{B}} \pm 0.51$ & $8.14^{\mathrm{A}} \pm 0.75$ & $<0.0001$ \\
Other behaviour & $78.20^{\mathrm{A}} \pm 1.90$ & $60.46^{\mathrm{C}} \pm 2.97$ & $64.38^{\mathrm{B}} \pm 2.67$ & $<0.0001$
\end{tabular}

${ }^{1}$ Mean $( \pm$ SD) in the same row with different superscripts differ significantly $(P<0.05)$.

${ }^{2}$ The data for each behaviour were recorded as minutes within 100 minute duration.

Table 4 Feather quality and gait scores of ducks in three production systems

\begin{tabular}{lcccc}
\hline \multirow{2}{*}{ Item } & \multicolumn{3}{c}{ Rearing system } & Net \\
\cline { 2 - 4 } & Floor & Welfare & Nalue \\
\hline The total feather condition score $^{2}$ & 32.0 & 28.0 & 17.0 & - \\
Feather condition score $^{3}$ & $2.13^{\mathrm{A}} \pm 0.83$ & $1.87^{\mathrm{A}} \pm 0.99$ & $1.13^{\mathrm{B}} \pm 0.74$ & 0.016 \\
Gait score $^{3}$ & $1.73^{\mathrm{A}} \pm 1.91$ & $1.73^{\mathrm{A}} \pm 0.70$ & $1.27^{\mathrm{B}} \pm 0.46$ & 0.014 \\
\hline
\end{tabular}

${ }^{1}$ Mean $( \pm \mathrm{SD})$ in the same row with different superscripts differ significantly $(P<0.05)$.

${ }^{2}$ The total feather condition score was the sum of the scores of 15 ducks of each group.

${ }^{3}$ Scoring systems explained in Table 2.

There were no differences in fluctuating asymmetry values of leg length, leg width and wing length among the groups $(P>0.05$; Table 6$)$. There were no differences in ADFI among the groups $(P>0.05)$. In the FRS, ADG was higher than in the NRS $(P<0.05)$ while the FCR was lower than in the ducks in the NRS $(P$ $<0.05$; Table 7). In the WRS, FCR was higher than in FRS ducks $(P>0.05)$, but the difference was not significant. In the NRS, FCR was the highest in the three groups, and compared with the FRS, the difference was significant $(P<0.05)$. So, FRS and WRS did not differ in growth performance. The growth performance in the NRS was lower than in the FRS $(P<0.05)$.

There were no differences among treatments in the $\mathrm{pH}$ of pectorals and leg muscles, conductivity or drip loss (Table 7). 
Table 5 Proportion (\%) of ducks with gait scores (GS) of 1.2 or 3 in the three production systems

\begin{tabular}{lccc}
\hline Rearing system $^{2}$ & & Gait scores $^{\mathbf{1}}$ & \\
\cline { 2 - 4 } & GS = 1 (\%) & GS = 2 (\%) & GS = 3 (\%) \\
\hline Floor & 33.3 & 60.0 & 6.67 \\
Welfare & 40.0 & 46.7 & 13.3 \\
Net & 73.3 & 26.7 & 0.00
\end{tabular}

${ }^{1}$ Scoring system explained in Table 2;

${ }^{2}$ Mean differences statistically significant between rearing systems: $X^{2}=44.7067, P<0.0001$.

Table 6 Mean fluctuating asymmetry (FA) of ducks in three production systems

\begin{tabular}{lcccc}
\hline $\begin{array}{l}\text { Fluctuating } \\
\text { asymmetry }\end{array}$ & Floor & Rearing system & P-value \\
\cline { 2 - 4 } & $0.84 \pm 0.69$ & Welfare & Net & 0.4775 \\
FA LL & $2.67 \pm 2.18$ & $0.56 \pm 0.68$ & $0.27 \pm 0.54$ & 0.0876 \\
FA LW & $1.61 \pm 1.19$ & $2.79 \pm 2.28$ & $0.00 \pm 0.00$ & 0.4348 \\
FA WL & & $3.58 \pm 3.49$ & $1.82 \pm 1.46$ & \\
\hline
\end{tabular}

LL: leg length; LW: leg width; WL: wing length.

${ }^{2}$ Means $( \pm \mathrm{SD})$ in the same row were not significantly different at $P<0.05$.

Table 7 Mean growth performance and meat quality of ducks in three production systems

\begin{tabular}{|c|c|c|c|c|}
\hline \multirow{2}{*}{ Item $^{1}$} & \multicolumn{3}{|c|}{ Rearing system } & \multirow{2}{*}{$P$-value } \\
\hline & Floor & Welfare & Net & \\
\hline ADG (g/bird/day) & $59.2^{A} \pm 2.80$ & $54.2^{\mathrm{AB}} \pm 3.01$ & $49.6^{\mathrm{B}} \pm 5.89$ & 0.0219 \\
\hline ADFI (g/bird/day) & $185 \pm 5.43$ & $179 \pm 11.4$ & $166 \pm 21.2$ & 0.3192 \\
\hline FCR & $3.13^{B} \pm 0.09$ & $3.26^{A B} \pm 0.12$ & $3.45^{\mathrm{A}} \pm 0.18$ & 0.0219 \\
\hline Initial $\mathrm{pH}$ of pectoralis & $6.16 \pm 0.04$ & $6.20 \pm 0.13$ & $6.17 \pm 0.03$ & 0.8146 \\
\hline Initial pH of leg muscle & $6.22 \pm 0.13$ & $6.27 \pm 0.15$ & $6.29 \pm 0.08$ & 0.7577 \\
\hline Ultimate $\mathrm{pH}$ of pectoralis & $6.04 \pm 0.09$ & $6.11 \pm 0.14$ & $6.07 \pm 0.03$ & 0.5615 \\
\hline Ultimate $\mathrm{pH}$ of leg muscle & $6.09 \pm 0.05$ & $6.11 \pm 0.14$ & $6.17 \pm 0.07$ & 0.4609 \\
\hline Conductivity of pectoralis & $4.22 \pm 0.04$ & $4.26 \pm 0.08$ & $4.28 \pm 0.07$ & 0.4622 \\
\hline Conductivity of leg muscle & $4.18 \pm 0.04$ & $4.24 \pm 0.19$ & $4.28 \pm 0.13$ & 0.5816 \\
\hline Drip loss (\%) & $1.39 \pm 1.26$ & $1.08 \pm 0.71$ & $0.46 \pm 0.25$ & 0.3308 \\
\hline
\end{tabular}

ADFI: average daily feed intake; ADG: average daily weight gain; FCR: feed conversion ratio (g feed/g gain).

${ }^{1}$ Mean $( \pm \mathrm{SD})$ in the same row with different superscripts differ significantly $(P<0.05)$.

\section{Discussion}

Intensive production systems appear to be unfavourable to daily duck behaviour. However, if producers raising Cherry Valley ducks, consider their behavioural needs, this should not only benefit management, but also improve growth performance and economic returns. The WRS system seems to be a better production system, and has attracted more attention recently. In this trial, bathing and feather pecking of NRS ducks were more than FRS and WRS ducks. These results are consistent with the findings of Liste et al. (2012). Ducks with access to more water exhibit natural drinking and water-associated activities, for instance, straining and preening the plumage with water met the requirements of welfare (Heyn et al., 2009). 
It was consistent with the behaviour of NRS ducks. These authors indicated that daily behaviour of ducks was affected by changing the production system or environment.

Duck feathers are smooth and shiny, and despite the popularity of intensive production systems, ducks often have poor quality feathers, implying that their level of welfare could be reflected in feather quality, which is affected by disease, management and nutrition. In addition, temperature, humidity and air pollution levels are particularly important. The current study showed that the total feather condition score of NRS ducks was lower than the other two groups. These results may be because the feeding environment in the NRS was better. An earlier report showed that open water drinkers had a positive impact on feather condition (Heyn et al., 2009), which is consistent with the current findings.

The incidence of leg diseases in duck would decrease by changing production systems. These results demonstrate that gait defects were lowest in NRS, indicated that NRS was relatively more comfortable than the other groups, and apparently reduced the incidence of leg disease. It was previously reported that the WRS was better than the FRS (Arnould et al., 2004) because enrichment materials could stimulate duck activity, reduce duck fear and improve adaptability. This is not consistent with our findings, possibly because the selected sample was small. It was reported that ducks in the chicken bell drinker group had higher gait scores than ducks in the trough and bath groups (O'Driscoll et al., 2011). This is consistent with the current findings.

Welfare is not necessarily directly influenced by fluctuating asymmetry, but fluctuating asymmetry can be used to reflect the adaptability of animals. With the increase in stocking density, fluctuating asymmetry increased and welfare decreased (Buijs et al., 2012). Welfare and duck comfort levels could be reflected by the value of fluctuating asymmetry (Moller et al., 1995; Moller et al., 2003; Tuyttens et al., 2008). In this trial, fluctuating asymmetry was not affected by production system, suggesting that the growth of bone is not affected by production system.

Growth performance is the most direct index with which to assess duck production. In this trial, ADFI of FRS ducks was the highest, while the FCR of FRS ducks was the lowest, and the growth performance was not significantly different between FRS and WRS systems. This may be because ducks in the FRS are active.

After slaughter, $\mathrm{pH}$ is an important indicator of muscle glycolysis, meat quality and muscle acidity, which influence the colour, tenderness and storage period of meat. The concentration of lactic acid in muscles reflects $\mathrm{pH}$, and with the lactic acid accumulating, meat quality declines. In the current study, different production systems had little effect on muscle acidity, and there was little difference in the accumulation of lactic acid among the groups. Drip loss is a common indirect indicator of water-holding capacity, because water loss is negatively related to water-holding capacity. In this trial, acidity, conductivity and drip loss were not affected by production system, suggesting that these systems had little effect on water holding, which is consistent with the findings of Adebayo et al. (2009).

\section{Conclusions}

The conclusion was that the NRS system proved the best production system for welfare traits while the WRS and FRS were the two best production systems on growth performance.

\section{Acknowledgements}

The authors are thankful to the staff in the Department of Animal Nutrition and Feed Science, College of Animal Science and Technology, Huazhong Agricultural University, Wuhan, China. This work was supported by the innovation team of Natural Science Funds of Hubei Province, Nutrition Regulation and Feed Safety of Pigs (2013CFA010), The Study of Improvement of Duck Breeding and the Technology of Efficient Health Breeding (2006 AA202A04).

\section{References}

Adebayo, I.A., Awoniyi, T.A.M. \& Akenroye, A.H., 2009. Growth performance and meat wholesomeness of broiler chickens reared on different types of litter materials. J. Food Agric. Environ. 7, 209-213.

Amado, M.F., Xavier, D.B., Boere, V., Torres-Pereira, C., McManus, C. \& Bernal, F.E.M., 2011. Behaviour of captive ostrich chicks from 10 days to 5 months of age. R. Bras. Zootec. 40 (7), 1613-1618.

Arnould, C., Bizeray, D., Faure, J.M. \& Leterrier, C., 2004. Effects of the addition of sand and string to pens on use of space, activity, tarsal angulations and bone composition in broiler chickens. Anim. Welf. 13, 87-94.

Buijs, S., Van Poucke, E., Van Dongen, S., Lens, L., Baert, J. \& Tuyttens, F.A.M., 2012. The influence of stocking density on broiler chicken bone quality and fluctuating asymmetry. Poult. Sci. 91, 1759-1767.

Dawkins, M.S., Donnelly, C.A. \& Jones, TA., 2004. Chicken welfare is influenced more by housing conditions than by stocking density. Nature 427, 342-344. 
Heyn, E., Damme, K., Bergmann, S., Remy, F., Kuster, Y. \& Erhard, M., 2009. Open water systems for species-appropriate housing of Peking ducks - effects on behaviour, feather quality and plugged up nostrils. Berl Munch Tierarztl Wochenschr. 122 (7-8), 292-301.

Jones, T.A., Waitt, C.D. \& Dawkin, M.S., 2009. Water off a duck's back: showers and troughs match ponds for improving duck welfare. Appl. Anim. Behav. Sci. 116 (1), 52-57.

Kestin, S.C., Knowles, T.G., Tinch, A.E. \& Gregory, N.G., 1992. Prevalence of leg weakness in broiler chickens and its relationship with genotype. Vet. Rec. 131, 190-194.

Liste, G., Kirkden, R.D. \& Broom, D.M., 2012. Effect of water depth on pool choice and bathing behaviour in commercial Pekin ducks. Appl. Anim. Behav. Sci. 139, 123-133.

Moller, A.P., Sanotra, G.S. \& Vestergaard, K.S., 1995. Developmental stability in relation to population density and breed of chickens Gallus gallus. Poult. Sci. 74, 1761-1771.

Moller, A.P. \& Manning, J., 2003. Growth and developmental instability. Vet. J. 166, 19-27.

NRC, 1994. Nutrient Requirements of Poultry (Ninth Revised ed.). National Academy Press, Washington D.C., USA.

O'Driscoll, K.K.M. \& Broom, D.M., 2011. Does access to open water affect the health of Pekin ducks (Anas platyrhynchos)? Poult. Sci. 90, 299-307.

SAS, 1995. Statistical Analysis System User's Guide: Version 6.12. SAS Inst., Inc., Cary. N.C., USA.

Tuyttens, F., Heyndrickx, M., De Boeck, M., Moreels, A., Van Nuffel, A., Van Poucke, E., Van Coillie, E., Van Dongen, S. \& Lens, L., 2008. Broiler chicken health, welfare and fluctuating asymmetry in organic versus conventional production systems. Livest. Sci. 113, 123-132.

Wang, X.Q., Chen, X., Tan, H.Z., Zhang, D.X., Zhang, H.J., Wei, S. \& Yan, H.C., 2013. Nutrient density and slaughter age have differential effects on carcass performance, muscle and meat quality in fast and slow growing broiler genotypes. Br. Poult. Sci. 54, 50-61.

Wechsler, B., Huber-Eicher, B. \& Nash, D.R., 1998. Feather pecking in growers: a study with individually marked birds. Br. Poult. Sci. 39, 178-185.

Xie, M., Jiang, Y., Tang, J., Wen, Z.G., Huang, W. \& Hou, S.S., 2014. Effects of stocking density on growth performance, carcass traits, and foot pad lesions of White Pekin ducks. Poult. Sci. 93, 1644-1648. 